\title{
Ayak bileği kırıkları sonrası görülen komplikasyonlar
}

\section{Complications after ankle fractures}

\author{
Kaan Irgıt, Hüseyin Bahadır Gökçen \\ LIV Hospital Ulus, Ortopedi ve Travmatoloji Kliniği, İstanbul
}

\begin{abstract}
Ayak bileği yaralanmaları en sık görülen ve genellikle cerrahi tedavi edilen yaralanmalardır. Gün geçtikçe ayak bileği kırığı sıklı̆ı artmakta ve daha komplike olan yaralanmalar ile karşılaşılmaktadır. Bu kadar sık görülen ve çok kolay komplikasyonlar ile karşılaşılan kırıklarda, ortopedistlerin sorun çıkabilecek riskli durumları tanıması ve bunlara göre önlemlerini alması gerekir. Bu makalede, bu komplikasyonlardan ve korunma önerilerinden bahsedilecektir.
\end{abstract}

Anahtar sözcükler: ayak bileği kırı̆ı; komplikasyon; malleol
Ankle fractures are among the most common injuries and the management is often surgical. Incidence of ankle fractures and unfortunately the complicated cases are increasing. Orthopaedic surgeons should be aware of the complications, the risk factors leading to these complications, and necessary precautions of these frequently seen injuries. The purpose of this review is to give the surgeons some guidelines to prevent such complications.

Key words: ankle fracture; complication; malleol

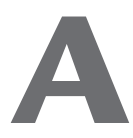

yak bileği kırıkları (ABK) ayrılmamış lateral malleol kırıklarından, ayak bileği açık kırıkı çıkıklarına kadar geniş bir spektrumu kapsar. Son yıllarda, özellikle kompleks kırıkların insidansı daha da artmaktadır. ${ }^{[1]}$ Ayak bileği kırıklarında cerrahi tedavide esas amaç anatomik redüksiyonun elde edilmesidir. Özellikle distal tibia ve fibula arasındaki anatomik ilişkinin iyi kurulamadığı zamanlarda, tibiotalar eklem biyomekaniği bozulur ve posttravmatik artroz meydana gelebilir. ${ }^{[2]}$ Cerrahi alan enfeksiyonları ABK sonrası görülen en sık komplikasyonlardan birisidir. Ameliyat sonrası enfeksiyon oluşması durumunda, bazen implantın üstündeki cilt nekroza gidip açılmakta ve bu bölgenin tedavisi ve rekonstrüksiyonu çok zor olabilmektedir. Bu nedenle, cerrahi alanda enfeksiyon riski içeren durumların önceden tespiti ve gereken önlemlerin alınması daha da önemlidir.

"Yaş" unsuru da komplikasyon gelişmesi açısından önemli bir risk faktörüdür. Genç hastalarda, yüksek enerjili travmalara bağlı kırıklar daha çok görülür. Yine gençlerde, kötü iyileşmiş bir kırığın hastanın hayatını olumsuz etkileme olasılığı ve posttravmatik artrit gelişme riski çok yüksektir. Yaşıılarda ise daha düşük enerjili travmalar ile kompleks kırıklar oluşabilir ve osteoporoza bağlı cerrahi sorunlar daha çok karşımıza çıkar. ABK'nda erken dönemde yumuşak doku komplikasyonları görülebilirken, ameliyatsız tedavinin de kendi içinde barındırdığı bazı komplikasyonlar mevcuttur. $\mathrm{Bu}$ durumlara yazının ilerleyen kısımlarında kısaca değinilecektir.

\section{EPIDEMIYOLOJi}

$A B K$, tüm kırıkların yaklaşık \%10'unu oluşturur ve cerrahi olarak en sık tedavi edilen kırıklardandır. ${ }^{[3]}$ En sık yaralanma mekanizması yürürken olan düşmelerdir. ${ }^{[1]}$ Erkeklerde görülme yaşı ortalama 45, kadınlarda ise 58'dir. ${ }^{[1]}$ Dünya nüfusu yaşlandıkça ve osteoporoz arttıkça, bu kırıkların da insidansının artması ve daha komplike yaralanmaların görülmesi kaçınılmazdır. ${ }^{[4]}$ Özellikle unimalleolar, stabil ve ayrılmamış ABK'nın ameliyat edilmeden tedavisi mümkündür. Ancak bimalleolar ve trimalleolar kırıklar instabil kabul edilir ve genellikle cerrahi tedavileri gerekir. Günümüzde cerrahi tedavi yöntemleri olarak; plak-vida, eksternal fiksator, kanal içi çivi veya bazı özel geliştirilmiş implantlar

- İletişim adresi: Doç. Dr. Kaan Irgıt, Canan Sok. No: 5, Ulus, İstanbul Tel: 0312 - 4261450 / 534 e-posta: kaanirgit@yahoo.com

- Geliş tarihi: 3 Mayıs $2016 \quad$ Kabul tarihi: 3 Mayıs 2016 
kullanılır. ${ }^{[5]}$ Plak-vida, özellikle osteoporotik durumlarda veya kompleks kırıklarda oldukça iyi tespit imkanı sağlar. ${ }^{[5]}$ Obez, geriatrik veya diyabetik hastalarda komplikasyonları azaltmak açısından, kilitli, sabit açılı sistemlerin kullanılması önerilmektedir. ${ }^{[6,7]}$ Kilitli plak kullanmanın avantajı, periosteal dolaşımın korunması ve bu implantın bükülme ve torsiyonel kuvvetlere karşı konvansiyonel plağa göre daha dayanıklı olmasıdır. ${ }^{[8]}$

Sindezmoz yaralanmaları, posterior malleol kırığı ve vertikal yerleşimli mediyal malleol kırıkları, komplikasyonlar açısından kendi içinde ayrıca riskler içerir.

\section{Sindezmoz Yaralanması}

Sindezmoz tibia ve fibula arasında kıkırdak içermeyen ve dört adet bağ tarafından meydana getirilmiş bir eklemdir. Bunlardan posterior tibiofibular bağ (PTFB) en güçlüsüdür ve transvers bağ ile birlikte sindezmotik direncin \%42'sini sağlar. ${ }^{[9]}$ Fibula kırı̆̆ının yüksekliği ile sindezmozdaki instabilite ilişkili değildir. Bu nedenle, instabilitenin mutlaka cerrahi sırasında dinamik testler ile doğrulanması gerekir. Sindezmoz vidasının ameliyattaki bu testlere göre konması gerekir; gereksiz sindezmoz vidası uygulamasından kaçınılmalıdır. ${ }^{[10]}$ Cotton testi (lateral fibula translasyon testi), eksternal rotasyon testi veya sagittal plan stres testi sindezmotik instabiliteyi değerlendirmek için kullanılan testlerdir ve tek başlarına hiçbirinin duyarlılığı yeterli olmadığı için kombine kullanılmaları gerekir. ${ }^{[1]}$ Sindezmozun anatomik restorasyonu, iyi bir klinik sonuç elde etmek için şarttır. Son dönemlerdeki bilgisayarlı tomografi (BT) çalışmaları, sindezmotik malredüksiyonun sanılandan çok daha fazla olduğunu ortaya koymaktadır. ${ }^{[12-14]}$ Ameliyat içinde her iki ayak bileğinin lateral floroskopik görüntülerini alarak, sağlam taraf ile karşılaştırma yapılması en doğru sindezmotik redüksiyonu sağlamakta yardımcı olur. Elgafy ve ark., özellikle tibiofibular eklemleşmesi düz olan hastalarda, redüksiyon klempinin pozisyonunun önemini vurgulamıştır. ${ }^{[15]}$ Sindezmoz vidasının yanlış yerleştirilmesi çeşitli komplikasyonlara yol açarken, gereksiz yere sindezmotik vida kullanılmasından kaçınılması gerektiği de bildirilmektedir. ${ }^{[16,17]}$

Sindezmoz vidasının yerleşimi, büyüklüğü, sayısı ve çıkarılma durumu da komplikasyonlara yol açabilir. Ekleme $2 \mathrm{~cm}$ mesafede ve $4 \mathrm{~cm}$ 'den daha proksimale yerleştirilen sindezmoz vidalarının, peroneal arterin perforan dalını yaralama, dolayısıyla sindezmotik bölge iyileşmesini bozma riski vardır. ${ }^{[18]}$ Sindezmoz tespiti için konulan vidalar, tercihe göre, ameliyat sonrası üçüncü aydan sonra çıkarılabilir. Sindezmotik vidalar çıkarılmaz, yerinde bırakılır ise kırılabilir (Şekil 1). Bu durum fonksiyonel bir sorun teşkil etmemesine rağmen, hastaların bir kısmı psikolojik olarak rahatsız olurlar.

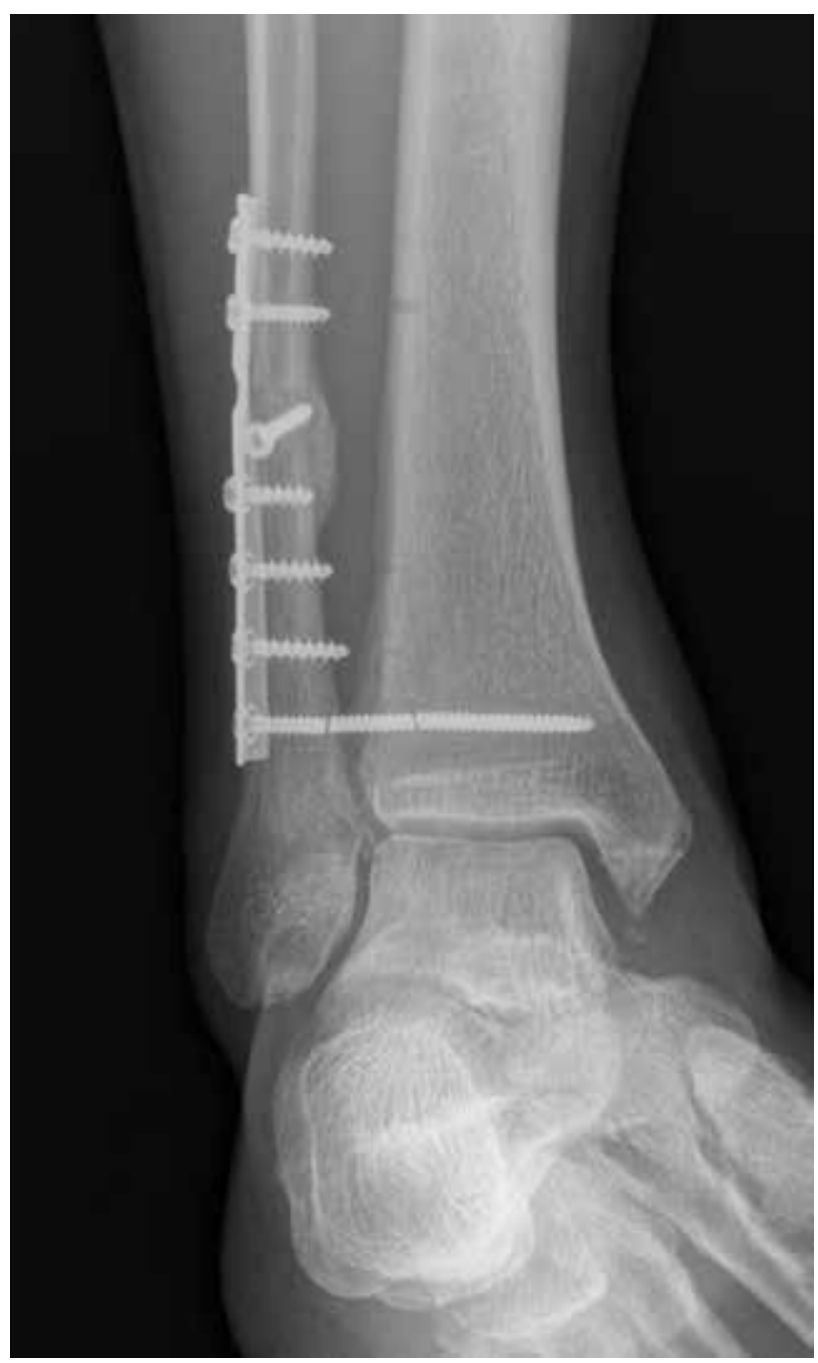

Şekil 1. Sindezmoz vidasında kırılma.

Sindezmoz tespitinde, son yıllarda kullanımı gittikçe artmakta olan sütür-düğme implantları ile de bildirilmiş pek çok komplikasyon mevcuttur. Bunlar arasında; konulan dügümün ele gelmesi, cilt irritasyonu, granülom oluşumu, yara sorunları, enfeksiyon ve osteomiyelit sayılabilir. ${ }^{[19,20]}$ Schepers ve ark., bir derlemede, yaklaşık 220 hastanın 22'sinde (\%10), çeşitli nedenlerden dolayı bu implantların çıkarılması gerektiğini göstermişlerdir. ${ }^{[21]}$

\section{Posterior Malleol Kırığı}

ABK'nın yaklaşık \%14-44'ünde posterior malleol kırığı görülür ve bu kırıkların sonuçları daha kötüdür. ${ }^{[5]}$ İzole yaralanmaların oranı ise sadece \%1'dir. ${ }^{[22]}$ BT çaış̧malarına göre, posterior malleol kırıkları çok değişik varyasyonlarda olabilir. ${ }^{[23,24]}$ 
Uzun yıllar, posterior malleoldaki kırık parçanın büyüklüğünün cerrahi karar alırken önemli olduğu öngörülmüştür. Ancak, henüz literatürde bu konu ile ilgili bir fikir birliği yoktur. Genellikle kullanılan cerrahi endikasyon, parçanın tibia plafondunun yüzey alanının \%25'inden daha büyük veya $2 \mathrm{~mm}$ 'den daha fazla ayrılmış olmasıdır. ${ }^{[5]}$ Hak ve ark.'na göre, büyük posterolateral parçaların, transvers tip kırıkların ve fibula redüksiyonu ile oturmayan parçaların tespiti gerekmektedir. ${ }^{[5]}$ Miller'a göre, lateral ve mediyal malleol tespiti sonrası talusta posterior rezidüel subluksasyon olması, mutlak bir cerrahi endikasyondur. ${ }^{[25]}$

Son zamanlardaki çalışmalar göstermiştir ki, boyutuna bakılmaksızın posterior malleol kırıklarının tespiti, hem stabiliteye katkıda bulunur hem de klinik sonuçların daha iyi olmasını sağlar. ${ }^{[12,22,25]}$

\section{Mediyal Malleol Vertikal Kırıkları}

Mediyal malleol vertikal kırıkları da ABK'nın yaklaşık \%5'inde meydana gelir. ${ }^{[26]}$ Vertikal kırıkların iyi değerlendirilmemesi ve yanlış tespiti ciddi komplikasyonlara yol açabilir. Çoğu mediyal malleol vertikal kırı̆̆ı, destek plağı veya kırık hattına dik vidalar ile tespit edilebilir. Standart AO prensiplerinin burada da uygulanması, komplikasyon risklerini azaltacaktır. ${ }^{[5]}$

\section{KOMPLIKASYONLAR}

ABK'nın tedavisinde \%1-40 arası komplikasyon görülebilir. ${ }^{[27,28]} A B K$ cerrahisinde komplikasyonlar, perioperatif, erken postoperatif ve geç postoperatif olarak ayrılabilir. ${ }^{[28]}$ Diyabet, periferik vasküler hastalık ve açık kırıklar, ameliyat sonrası erken dönemde komplikasyon görülmesi için risk faktörleridir. ${ }^{[27]}$

\section{Yara Komplikasyonları ve Enfeksiyon}

ABK ameliyatları sonrası yara problemi görülme riski \%7-13 arasında değişir. Ek morbiditesi ve risk faktörü olan hastalarda ise komplikasyon görülme riski daha da artar (Tablo 1). Yara komplikasyonları; yara nekrozu, yara iyileşme gecikmesi, yüzeyel enfeksiyon veya derin enfeksiyon şeklinde olabilir.

Yara yeri enfeksiyonu (YYE), ABK ameliyatları sonrası en sık görülen komplikasyondur. Literatürde $A B K$ ameliyatları sonrası YYE \%1,4-5,5 arasında bildirilmiştir; ancak bu oran diyabetiklerde \%20'ye çıkabilir. ${ }^{[21,27,29]}$ Uygun tedaviye rağmen tekrarlayan enfeksiyon görülme riski de azımsanmayacak kadar fazladır. Ameliyat sonrası enfeksiyonlar, hastanede kalış süresini uzatıp ciddi maliyetlere neden olur. ${ }^{[30]}$ Bunun yanı sıra YYE, kalıcı arazlara, ampütasyonlara, hatta ölüme bile yol açabilir. ${ }^{[27]}$

Üstündeki cilt ve cilt altı dokusu ince olduğu için, ayak bileği civarındaki yara sorunları süratle kemiği
Tablo 1. Ayak bileği kırıkları sonrası görülen komplikasyonlar için risk faktörleri

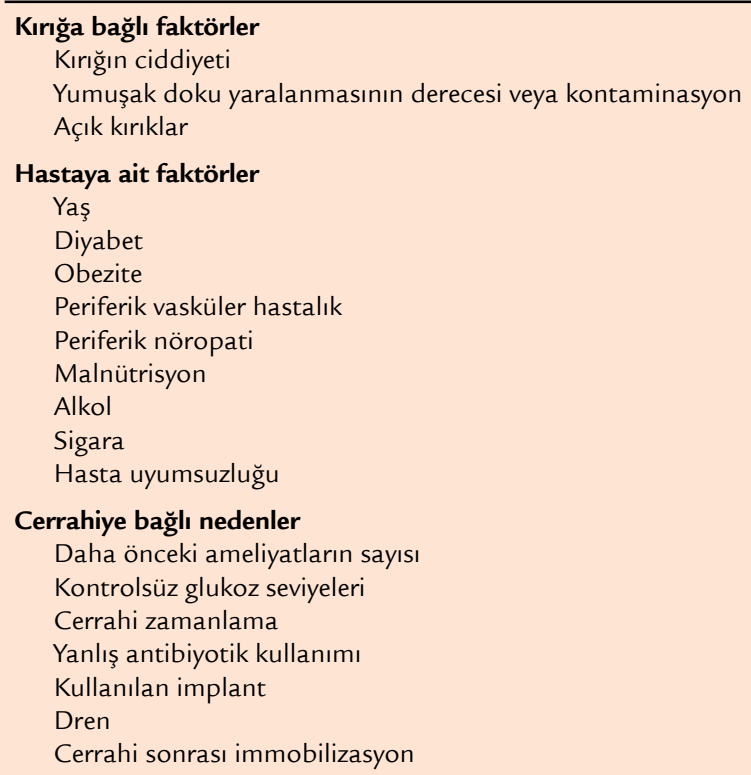

veya implantı kontamine edebilir. ${ }^{[31]}$ Tedavide amaç, kırığın anatomik kaynamasını sağlarken yumuşak dokuyu korumak ve kronik bir enfeksiyonun oluşmasını engellemektir. Bu amaçla; erken dönemde debridman, nekrotik dokuların uzaklaştırılması ve uzun süreli antibiyotik tedavisi gereklidir. İmplantın kaynama olmadan çıkarılması redüksiyon kaybı ve ciddi fonksiyon kaybına yol açabileceğinden, stabil olan implantlar mümkün olduğu kadar yerinde tutulmaya çalışılmalıdır. ${ }^{[31,32]}$ Ancak, biyofilm oluşmuş geç enfeksiyonlarda, çoğunlukla implantın da çıkarılması gerekir. ${ }^{[33]}$ Cerrah kararını, kırı̆ı̆ın ve redüksiyonun o anki stabilitesine, kırığın kaynama durumuna ve çıkarılmayan plağın enfeksiyona ne kadar katkıda bulunduğuna göre vermelidir. Bu her zaman kolaylıkla verilebilecek bir karar değildir. Rightmire ve Berkes, implantların yerinde bırakıldığı enfekte $A B K$ tedavileri sonucunda $\% 70$ oranında kaynama bildirmişlerdir. ${ }^{[34]}$ İmplantın halen tespit sağladığı, anatomik redüksiyonun var olduğu, nekrotik dokunun olmadığı ve erken donemde müdahale edilen enfekte durumlarda, enfeksiyon ortadan kaldırılamasa bile muhtemelen yavaşlatılmakta ve kaynama bu şekilde sağlanmaktadır. ${ }^{[35]}$ Erken dönemde açık yaraların üstünü kapatmak için, negatif basınçlı vakum sistemleri veya flep cerrahisinden de yararlanılabilir. ${ }^{[36-38]}$ Flep cerrahisinin ilk yedi gün içinde yapılması başarı şansını arttıracaktır. ${ }^{[37]}$ Bu konuda en uygun tedavi yaklaşımının ne olduğu halen tartışmalıdır. 


\section{Malredüksiyon}

Ayak bileği mortis anatomisinin tekrar oluşturulamamasının ve tibiotalar eklemdeki yük dağılımında değişiklikler olmasının, uzun dönem sonuçları kötü etkilediği literatürde çok defa gösterilmiştir. ${ }^{[39,40]}$ Kırığın çok parçalı veya kemik kalitesinin kötü olması sonucu veya teknik hatalardan dolayı, $A B K$ cerrahisi sonrası rezidüel deplasman görülebilir. ${ }^{[41,42]}$ Son dönemlerdeki BT çalışmaları, sindezmoz redüksiyonlarının da sanıldığından daha başarısız olduğunu göstermiştir. [12,25] Soohoo'nun geniş popülasyonlu çalışmasında, 57.183 hastanın sadece $\% 0,8^{\prime} i$ ilk üç ayda revizyona alınmıştır. ${ }^{[27]}$ Maalesef, literatürde hangi tip malredüksiyonlara erken cerrahi müdahale gerektiğine dair bir çalışma yoktur.

\section{Redüksiyon Kaybı ve Kötü Kaynama}

Kırk konfigürasyonunun kompleks olması, redüksiyon yetersizliği veya kaybı, sonuçta kötü kaynamaya neden olur ve eklem kıkırdağındaki bu düzensizlik, ileride kronik ağrıya, fonksiyonel kayba ve posttravmatik artrite yol açar. Giannini'ye göre, kötü kaynaması olan hastalar yürürken ve fiziksel aktivite esnasında olan ağrıdan, şişmeden veya eklem sertliğinden yakınırlar. ${ }^{[43]}$ Fibulanın kısa veya rotasyon kusuru ile kaynaması, ayak bileği kırıkları cerrahisi sonrası en sık yaşanan ve aynı zamanda en zor tedavi edilen kötü kaynama tipidir. ${ }^{[40,43,44]}$ Radyolojik olarak, mediyal ve lateral mesafede asimetri, talus dönüklügü veya talar kayma, talar subluksasyon ve fibulada kısalma olması ile tanı konur (Şekil 2). Fibula kısalığına tanı koymak nispeten kolay iken, malrotasyonu BT ile değerlendirmek, mümkünse üç boyutlu rekonstrüksiyon yapmak gerekmektedir. ${ }^{[43]}$

\section{Posttravmatik Osteoartrit}

ilk kırı̆ın ciddiyeti neticesinde ciddi eklem kıkırdak hasarı olması, talokrural eklem instabilitesi bulunması ve kırıklarda kötü kaynama sonucu post-travmatik osteoartrit (OA) gelişebilir (Şekil 3a). ${ }^{[27]} \mathrm{Hem}$ kırıklar, hem de bağ yaralanmaları sonrası OA görülebilir, ancak hastaların \%37'sinin etiyolojisinde rotasyonel bir kırık vardır. ${ }^{[45]}$ Lindsjo, ileriye dönük çalışmasında, post-travmatik OA oranını \%14 bulmuşken ${ }^{[46]}$, Soohoo'nun 57.183 hasta üzerindeki araştırmasında, OA bağlı füzyon veya artrodez oranı \%1 olarak bildirilmiştir (Şekil 3b). ${ }^{[27]}$ Bu çalışmada, trimalleolar veya açık kırık varlığı, tek başına bir risk faktörü olarak göze çarpmaktadır. Osteoartrit oluşumu açısından, fibulanın kötü kaynaması da başka bir risk faktörüdür.

\section{Kaynamama}

ABK sonrası gerçek kaynamama oranları bilinmemek ile birlikte, konservatif tedavi edilmiş kırıklarda

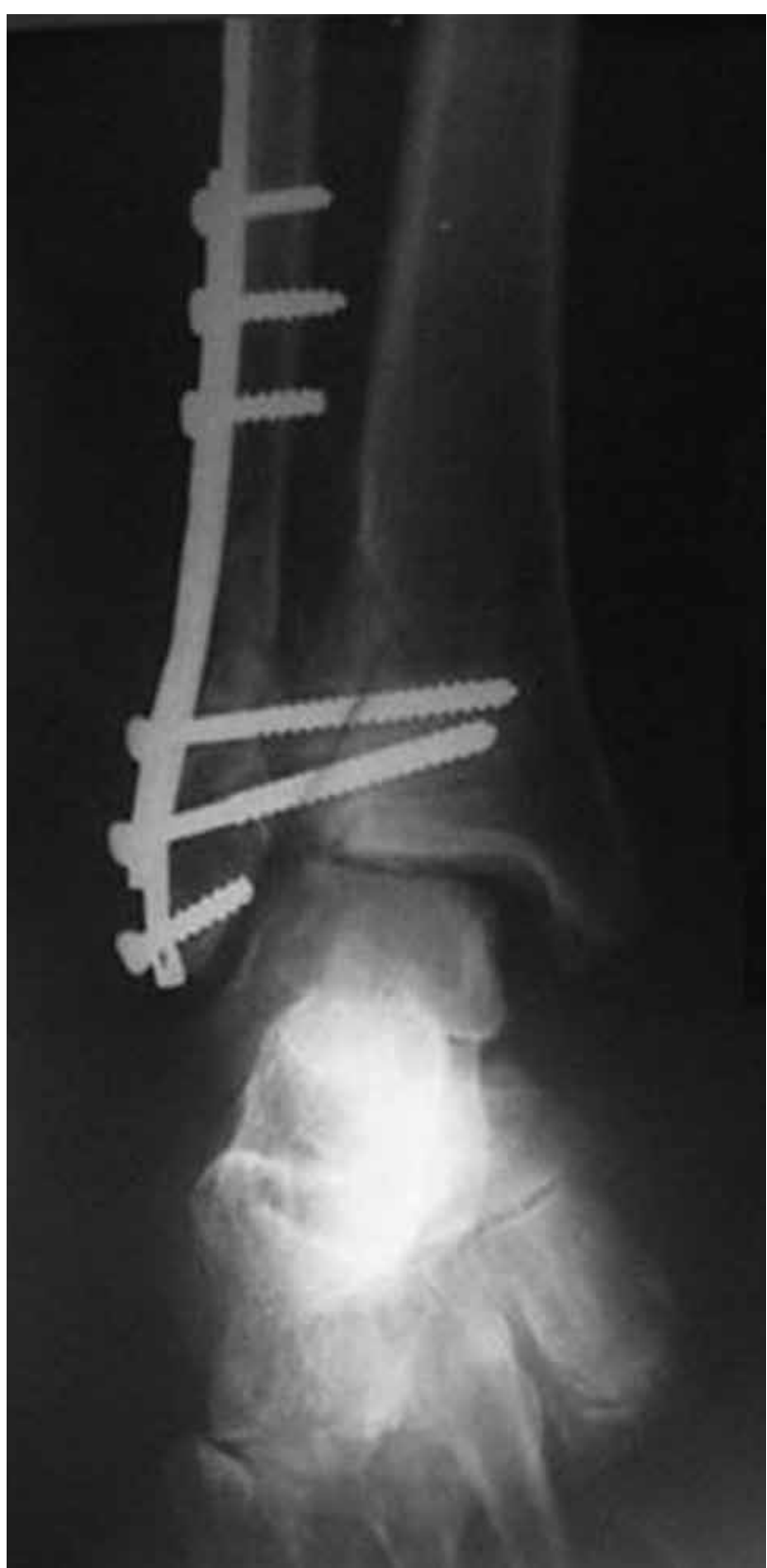

Şekil 2. Malredüksiyon sonrası kötü kaynama. Fibulada kısalma, mediyal eklem aralığında artma ve talar kayma izleniyor.

Donken ve ark. \%2 kaynamama tespit etmişlerdir. ${ }^{[47]}$ Kırık tespitinde yetersizliğe bağlı anormal hareket veya aşırı periost sıyrılmasına bağlı damarlanmanın bozulması kaynamamaya yol açabilir. Bunların yanı sıra; enfeksiyon, diyabet, aşıı alkol kullanımı ve ileri yaş da bu komplikasyonun oluşmasına katkıda bulunur. ilk kırıktan altı ay sonra ağrısı olan her ABK olgusunda kaynamama akla getirilmelidir. 

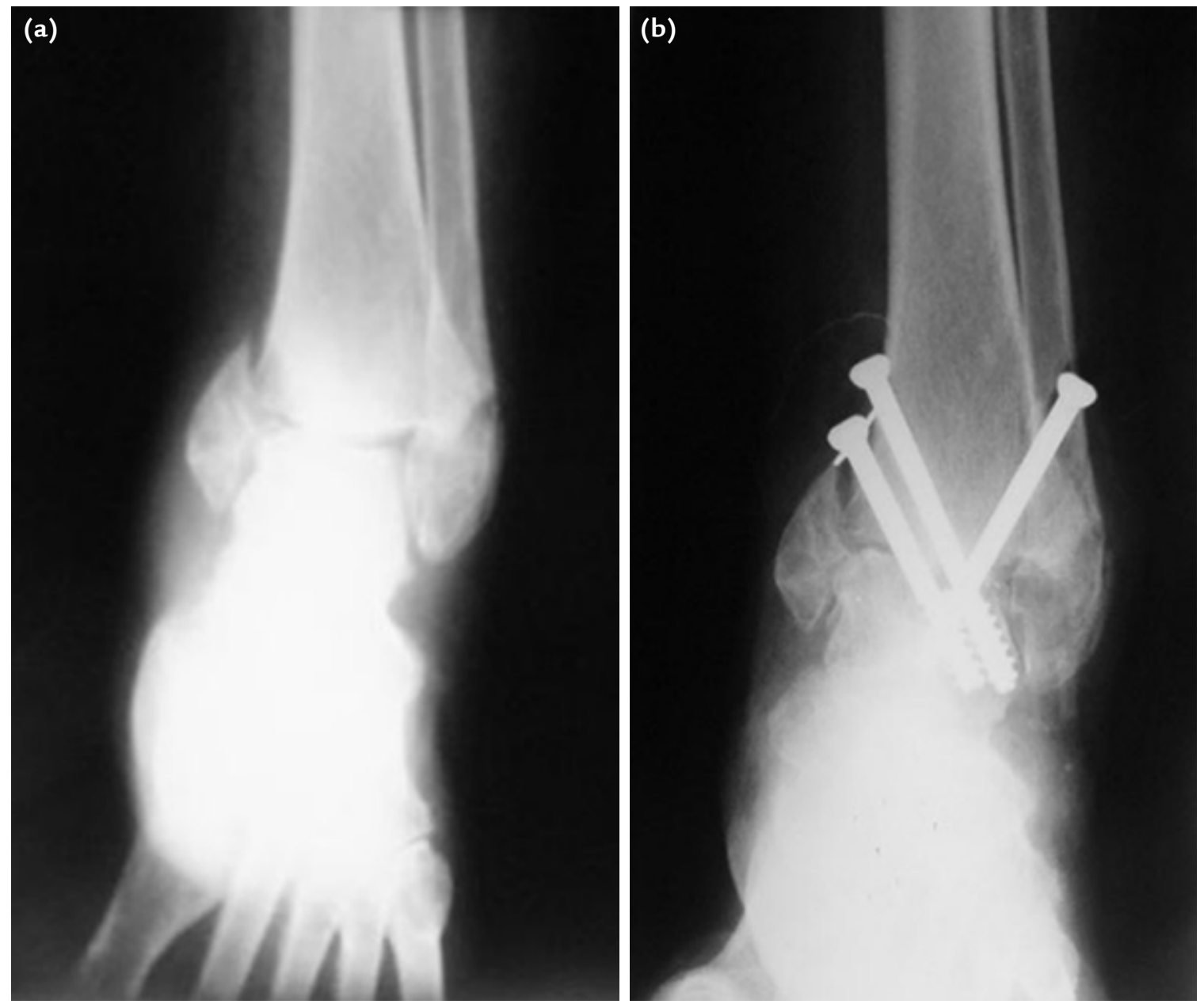

Şekil 3. a, b. Başarısız tedavi ve kaynamama sonrası gelişen osteoartrit (a). Ayak bileği artrodezi ile osteoartrit tedavisi (b).

\section{Nörolojik Komplikasyonlar}

En sık bildirilen nörolojik komplikasyon süperfisiyel peroneal sinir nörinomudur. ${ }^{[48]}$ Süperfisiyel peroneal sinir, fibulaya yapılan lateral yaklaşım esnasında risk altındadır ve kesildiği takdirde gelişen nörinom, kronik ağrıya yol açar (Şekil 4). Semptomatik yüzeyel peroneal sinir yaralanmalarının \%15 oranında görüldüğü bildirilmiştir. ${ }^{[48]}$

Fibulaya posterolateral yaklaşım sırasında risk altında olan sinir ise sural sinirdir ve yaralanması sonrası, ağrılı nörinom ve ayağın lateral kenarında hissizlik meydana gelir. ${ }^{[48]}$

\section{İmplant Üzerinde Kronik Ağrı}

İmplant irritasyonu \%23 oranında görülür ve bazı hastalarda implantı çıkarmak gerekebilir. ${ }^{[49]}$ Ancak, \%50 hastada implant çıkarılmasına rağmen ağrılar devam edebilir ve bu konuda hastalara bilgi vermek gerekir.

\section{Tromboembolik Komplikasyonlar}

ABK sonrası klinik olarak tespit edilebilen tromboembolik olay çok azdır ve muhtemelen de tromboprofilaksiden etkilenmemektedir. Soohoo ve Pelet, farklı çalışmalarda, tromboembolik olay insidansını \%3, pulmoner emboli insidansını ise $\% 0,3$ olarak bildirmişlerdir. ${ }^{[27,50]}$ Stabil kırıkların alçı tedavisi sonrası da bildirilen tromboembolik olaylar vardır. Yaşlı hastalarda, kanserli hastalarda, turnike kullanımının uzadığı ve yük vermenin geciktirildiği durumlarda, sigara içme veya daha önce geçirilmiş tromboembolik olay öyküsü olan hastalarda, hamilelerde ve hormon tedavisi görenlerde risk daha yüksektir. Bu nedenle, riskli hastalarda tromboprofilaksi uygulanması düşünülebilir. 


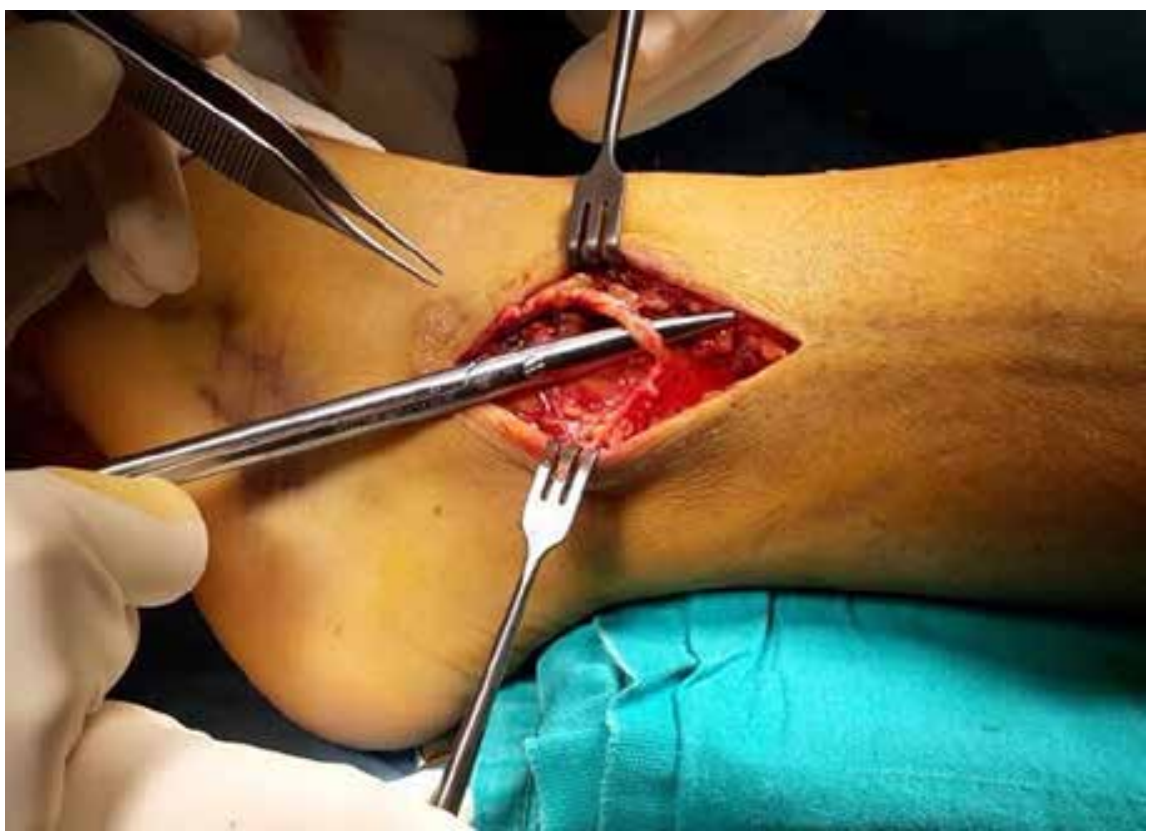

Şekil 4. Süperfisiyel peroneal sinirin lateral yaklaşım sırasında ortaya konulması.

\section{KOMPLIKASYON AÇISINDAN YÜKSEK RISK GRUPLARI}

\section{Diyabetik Hastalar}

Günümüzde, özellikle gelişmekte olan ülkelerde, diyabet insidansı ve diyabete bağlı komplikasyonlarda bir artış vardır. Diyabetik hastalardaki açık ve kapaIı ABK'nda komplikasyon oranları da artmaktadır. Diyabetik hastalarda ABK cerrahi tedavisi sonrası yara komplikasyonu oranları, kapalı ve açık kırıklarda sırasıyla $\% 32$ ve $\% 64$ arasında bulunmuştur. ${ }^{[5]}$ Özellikle diyabetik nöropatisi olan hastaların alçı ile tedavisi, katastrofik sonuçlara yol açabilir. Diyabet, sadece komplikasyonlar açısından bir risk faktörü değildir; aynı zamanda artmış mortalite, uzamış hastane kalış süreleri ve yüksek tedavi maliyetlerinden de sorumludur. ${ }^{[27]}$ Diyabetik nöropatisi veya vaskülopatisi olan hastalarda, komplike olmayan diyabetik hastalara göre komplikasyon görülme olasılığı altı kat daha fazladır.

\section{Obez Hastalar}

Obez hastalarda ameliyat kararı alınmadan önce, obezlerdeki Tip 2 diyabet insidansı da göz önüne alınmalıdır. Her ne kadar komplikasyonları azaltmak için konservatif tedavi tercihi çekici gelse de; redüksiyon kaybı, nöropatik hastalardaki alçı sorunları, yük vermeme konusundaki uyumsuzluk gibi nedenlerden dolayı, cerrahi tedavi tercihi doğru endikasyonlarda yine daha ön plandadır. Bir başka deyişle, cerrahiden kaçınmak her zaman komplikasyonları ortadan kaldırmaz.

Obez, iri ve diyabetik hastalarda redüksiyon kaybı gibi komplikasyonlardan kaçınmak için daha kuvvetli kilitli plakların kullanılması, ek plak veya eksternal fiksatörler ile tespitin desteklenmesi ve hastaların daha geç bastırılması önerilmektedir. Özellikle obez hastalarda erken yük verdirmek, redüksiyon kaybı açısından en büyük riski oluşturur.

Sindezmotik yaralanmaların cerrahi tedavisi sonrası redüksiyon kaybı ile obezite arasında da ciddi ilişki vardır. ${ }^{[51]}$

\section{Yaşlı Hastalar}

Geriatrik hastalar, kemik kalitelerinin kötü olması ve ek morbiditeleri nedeniyle, özellikle sorunludur. Ileri yaş, YYE gelişmesi veya mortalite açısından ciddi bir risk faktörüdür. Yaşı hastalarda cerrahi riskler ameliyat öncesinde dikkatlice çok iyi gözden geçirilmelidir. illginç bir şekilde, ne osteoporoz ne de önceden geçirilmiş osteoporotik $A B K$, yaşlı hastalarda bir risk faktörü oluşturmamaktadır. ${ }^{[5]}$

Ancak, osteoporoz varlı̆̆ı redüksiyon kaybı açısından bir risk faktörüdür; bu nedenle, yaşlı hastalarda kilitli plak kullanmak avantaj sağlayabilir. Osteopenik ve osteoporotik hastalarda, stabil bir tespit elde etmek çoğunlukla zor olmaktadır. 
Sonuç olarak, dünyada komplike ayak bileği kırıklarının görülme insidansı artmaktadır. Çok sık görülen ve sıklıkla da cerrahi tedavisi gereken ayak bileği kırıklarının, ameliyat öncesinde radyolojik olarak çok dikkatli incelenmesi gerekir. Her hastaya bilgisayarlı tomografi çekilerek kırık konfigürasyonuna hakim olmak, cerrahi endikasyonu olduğu düşünülen instabil kırıklarda ve diyabetik, yaşı ı osteoporotik hastalarda komplikasyon risklerini azaltabilir. Ameliyat öncesi hastaların ek morbiditelerini de düşünerek, implant seçimini ve planını buna göre yapmak gereklidir. Hastaların yük vermesi ve rehabilitasyonu da hastaya göre değişiklikler gösterebilir, kişiye özel rehabilitasyon planlanabilir. Olası ciddi komplikasyonlar yönünden hastaların da mutlaka bilgilendirilmesi ve tedaviye uyumlarının sağlanması tedavi başarısını arttırabilir.

\section{KAYNAKLAR}

1. Thur CK, Edgren G, Jansson KÅ, Wretenberg P. Epidemiology of adult ankle fractures in Sweden between 1987 and 2004: a population-based study of 91,410 Swedish inpatients. Acta Orthop 2012;83(3):276-81. Crossref

2. Ramsey PL, Hamilton W. Changes in tibiotalar area of contact caused by lateral talar shift. J Bone Joint Surg Am 1976;58(3):356-7.

3. Schepers T, De Vries MR, Van Lieshout EM, Van der Elst $M$. The timing of ankle fracture surgery and the effect on infectious complications; a case series and systematic review of the literature. Int Orthop 2013;37(3):489-94. Crossref

4. Zaghloul A, Haddad B, Barksfield R, Davis B. Early complications of surgery in operative treatment of ankle fractures in those over 60: a review of 186 cases. Injury 2014;45(4):780-3. Crossref

5. Hak DJ, Egol KA, Gardner MJ, Haskell A. The "not so simple" ankle fracture: avoiding problems and pitfalls to improve patient outcomes. Instr Course Lect 2011;60:73-88.

6. Lynde MJ, Sautter T, Hamilton GA, Schuberth JM. Complications after open reduction and internal fixation of ankle fractures in the elderly. Foot Ankle Surg 2012;18(2):1037. Crossref

7. Olsen JR, Hunter J, Baumhauer JF. Osteoporotic ankle fractures. Orthop Clin North Am 2013;44(2):225-41. Crossref

8. Wagner M. General principles for the clinical use of the LCP. Injury 2003;34 Suppl 2:B31-42.

9. Ogilvie-Harris DJ, Reed SC, Hedman TP. Disruption of the ankle syndesmosis: biomechanical study of the ligamentous restraints. Arthroscopy 1994;10(5):558-60.

10. Pakarinen $H$, Flinkkilä $T$, Ohtonen $P$, Hyvönen $P$, Lakovaara $M$, Leppilahti J, Ristiniemi J. Intraoperative assessment of the stability of the distal tibiofibular joint in supinationexternal rotation injuries of the ankle: sensitivity, specificity, and reliability of two clinical tests. J Bone Joint Surg Am 2011;93(22):2057-61. Crossref

11. Van den Bekerom MP. Diagnosing syndesmotic instability in ankle fractures. World J Orthop 2011;2(7):51-6. Crossref

12. Gardner MJ, Demetrakopoulos D, Briggs SM, Helfet DL, Lorich DG. Malreduction of the tibiofibular syndesmosis in ankle fractures. Foot Ankle Int 2006;27(10):788-92.
13. Franke J, von Recum J, Suda AJ, Grützner PA, Wendl K. Intraoperative three-dimensional imaging in the treatment of acute unstable syndesmotic injuries. J Bone Joint Surg Am 2012;94(15):1386-90.

14. Sagi HC, Shah AR, Sanders RW. The functional consequence of syndesmotic joint malreduction at a minimum 2-year follow-up. J Orthop Trauma 2012;26(7):439-43. Crossref

15. Elgafy $H$, Semaan $H B$, Blessinger $B$, Wassef A, Ebraheim NA. Computed tomography of normal distal tibiofibular syndesmosis. Skeletal Radiol 2010;39(6):559-64. Crossref

16. Vasarhelyi A, LubitzJ, GiererP, GradI G, Rösler K, Hopfenmüller W, Klaue K, Mittlmeier TW. Detection of fibular torsional deformities after surgery for ankle fractures with a novel CT method. Foot Ankle Int 2006;27(12):1115-21.

17. Nimick CJ, Collman DR, Lagaay P. Fixation orientarion in ankle fractures with syndesmosis injury. J Foot Ankle Surg 2013;52(3):315-8. Crossref

18. Penera K, Manji K, Wedel M, Shofler D, Labovitz J. Ankle syndesmotic fixation using two screws: risk of injury to the perforating branch of the peroneal artery. J Foot Ankle Surg 2014;53(5):534-8. Crossref

19. Naqvi GA, Shafqat A, Awan N. Tightrope fixation of ankle syndesmosis injuries: clinical outcome, complications and technique modification. Injury 2012;43(6):838-42. Crossref

20. Hodgson P, Thomas R. Avoiding suture knot prominence with suture button along distal fibula: technical tip. Foot Ankle Int 2011;32(9):908-9.

21. Schepers T. Acute distal tibiofibular syndesmosis injury: a systematic review of suture-button versus syndesmotic screw repair. Int Orthop 2012;36(6):1199-206. Crossref

22. Irwin TA, Lien J, Kadakia AR. Posterior malleolus fracture. J Am Acad Orthop Surg 2013;21(1):32-40. Crossref

23. Haraguchi $N$, Haruyama $H$, Toga $H$, Kato F. Pathoanatomy of posterior malleolar fractures of the ankle. J Bone Joint Surg Am 2006;88(5):1085-92.

24. Yao L, Zhang W, Yang G, Zhu Y, Zhai Q, Luo C. Morphologic characteristics of the posterior malleolus fragment: a 3-D computer tomography based study. Arch Orthop Trauma Surg 2014;134(3):389-94. Crossref

25. Miller AN, Carroll EA, Parker RJ, Helfet DL, Lorich DG. Posterior malleolar stabilization of syndesmotic injuries is equivalent to screw fixation. Clin Orthop Relat Res 2010;468(4):1129-35. Crossref

26. McConnell T, Tornetta P 3rd. Marginal plafond impaction in association with supination-adduction ankle fractures: a report of eight cases. J Orthop Trauma 2001;15(6):447-9.

27. SooHoo NF, Krenek L, Eagan MJ, Gurbani B, Ko CY, Zingmond DS. Complication rates following open reduction and internal fixation of ankle fractures. J Bone Joint Surg Am 2009;91(5):1042-9. dCrossref

28. Leyes $M$, Torres $R$, Guillén P. Complications of open reduction and internal fixation of ankle fractures. Foot Ankle Clin 2003;8(1):131-47.

29. Wukich DK, Lowery NJ, McMillen RL, Frykberg RG. Postoperative infection rates in foot and ankle surgery: a comparison of patients with and without diabetes mellitus. J Bone Joint Surg Am 2010;92(2):287-95. Crossref

30. Whitehouse JD, Friedman ND, Kirkland KB, Richardson WJ, Sexton DJ. The impact of surgical-site infection following orthopaedic surgery at a community hospital and a university hospital: adverse quality of life, excess length of stay, and extra cost. Infect Control Hosp Epidemiol 2002;23(4):183-9. 
31. Thordarson DB, Ahlmann E, Shepherd LE, Patzakis MJ. Sepsis and osteomyelitis about the ankle joint. Foot Ankle Clin 2000;5(4):913-28.

32. Cyrochristos DJ, Papadopoulos O, Liapis C, Felekouras EL, Giannopoulos AM, Bastounis E. Coverage strategies in exposed implants. Am Surg 2009;75(11):1132-8.

33. Darouiche RO. Treatment of infections associated with surgical implants. N Engl J Med 2004;350(14):1422-9.

34. Berkes $M$, Obremskey WT, Scannell B, Ellington JK, Hymes RA, Bosse M; Southeast Fracture Consortium. Maintenance of hardware after early postoperative infection following fracture internal fixation. J Bone Joint Surg Am 2010;92(4):823-8. Crossref

35. Zalavras CG, Christensen T, Rigopoulos N, Holtom P, Patzakis MJ. Infection following operative treatment of ankle fractures. Clin Orthop Relat Res 2009;467(7):1715-20. Crossref

36. Bhattacharyya T, Mehta P, Smith M, Pomahac B. Routine use of wound vacuum-assisted closure does not allow coverage delay for open tibia fractures. Plast Reconstr Surg 2008;121(4):1263-6. Crossref

37. Hou Z, Irgit K, Strohecker KA, Matzko ME, Wingert NC, DeSantis JG, Smith WR. Delayed flap reconstruction with vacuum-assisted closure management of the open IIIB tibial fracture. J Trauma 2011;71(6):1705-8. Crossref

38. Liu DS, Sofiadellis F, Ashton M, MacGill K, Webb A. Early soft tissue coverage and negative pressure wound therapy optimises patient outcomes in lower limb trauma. Injury 2012;43(6):772-8. Crossref

39. Lloyd J, Elsayed S, Hariharan K, Tanaka H. Revisiting the concept of talar shift in ankle fractures. Foot Ankle Int 2006;27(10):793-6.

40. Thordarson DB. Patients with a crooked radiograph after ankle fracture: what to do? Foot Ankle Int 2012;33(4):355-8. Crossref
41. Horisberger M, Valderrabano V, Hintermann B. Posttraumatic ankle osteoarthritis after ankle-related fractures. J Orthop Trauma 2009;23(1):60-7. Crossref

42. Lübbeke A, Salvo D, Stern R, Hoffmeyer P, Holzer N, Assal M. Risk factors for post-traumatic osteoarthritis of the ankle: an eighteen year follow-up study. Int Orthop 2012;36(7):140310. Crossref

43. Giannini S, Faldini C, Acri F, Leonetti D, Luciani D, Nanni $M$. Surgical treatment of post-traumatic malalignment of the ankle. Injury 2010;41(11):1208-11. Crossref

44. van Wensen RJ, van den Bekerom MP, Marti RK, van Heerwaarden RJ. Reconstructive osteotomy of fibular malunion: review of the literature. Strategies Trauma Limb Reconst 2011;6(2):51-7. Crossref

45. Saltzman CL, Salamon ML, Blanchard GM, Huff T, Hayes A, Buckwalter JA, Amendola A. Epidemiology of ankle arthritis: report of a consecutive series of 639 patients from a tertiary orthopaedic center. lowa OrthopJ 2005;25:44-6.

46. Lindsjö U. Operative treatment of ankle fractures. Acta Orthop Scand Suppl 1981;189:1-131.

47. Donken CC, van Laarhoven CJ, Edwards MJ, Verhofstad MH. Misdiagnosis of OTA type B (Weber B) ankle fractures leading to nonunion. J Foot Ankle Surg 2011;50(4):430-3. Crossref

48. Jowett AJ, Sheikh FT, Carare RO, Goodwin MI. Location of the sural nerve during posterolateral approach to the ankle. Foot Ankle Int 2010;31(10):880-3. Crossref

49. Brown OL, Dirschl DR, Obremskey WT. Incidence of hardware-related pain and its effect on functional outcomes after open reduction and internal fixation of ankle fractures. J Orthop Trauma 2001;15(4):271-4.

50. Pelet S, Roger ME, Belzile EL, Bouchard M. The incidence of thromboembolic events in surgically treated ankle fracture. J Bone Joint Surg Am 2012;94(6):502-6. Crossref

51. Mendelsohn ES, Hoshino CM, Harris TG, Zinar DM. The effect of obesity on early failure after operative syndesmosis injuries. J Orthop Trauma 2013;27(4):201-6. Crossref 